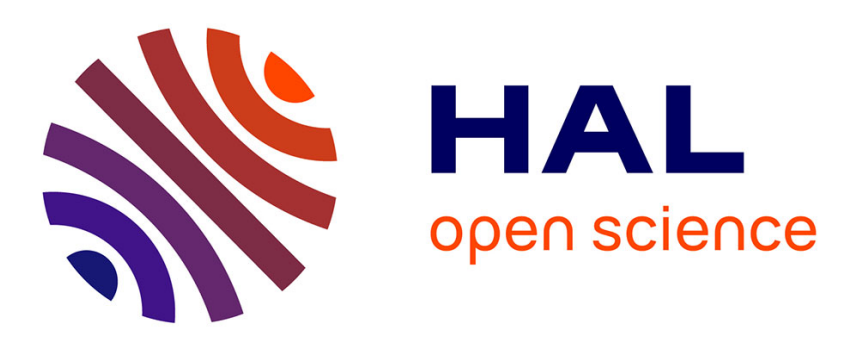

\title{
Anisotropic constitutive model of plasticity capable of accounting for details of meso-structure of two-phase composite material
}

\author{
Nathan Benkemoun, A Ibrahimbegovic, J.-B Colliat
}

\section{To cite this version:}

Nathan Benkemoun, A Ibrahimbegovic, J.-B Colliat. Anisotropic constitutive model of plasticity capable of accounting for details of meso-structure of two-phase composite material. Computers \& Structures, 2011, 90-91, pp.153-162. 10.1016/j.compstruc.2011.09.003 . hal-01380346

\section{HAL Id: hal-01380346 https://hal.science/hal-01380346}

Submitted on 14 Oct 2016

HAL is a multi-disciplinary open access archive for the deposit and dissemination of scientific research documents, whether they are published or not. The documents may come from teaching and research institutions in France or abroad, or from public or private research centers.
L'archive ouverte pluridisciplinaire $\mathbf{H A L}$, est destinée au dépôt et à la diffusion de documents scientifiques de niveau recherche, publiés ou non, émanant des établissements d'enseignement et de recherche français ou étrangers, des laboratoires publics ou privés. 


\title{
Anisotropic constitutive model of plasticity capable of accounting for details of meso-structure of two-phase material
}

\author{
N. Benkemoun, J.-B. Colliat and A. Ibrahimbegovic \\ LMT-Cachan (ENS-Cachan/CNRS/UPMC/PRES UniverSud Paris) \\ 61 avenue du Président Wilson, 94235 Cachan Cedex, France
}

\begin{abstract}
In this work, we discuss a novel anisotropic constitutive model of plasticity, which can be used to replace the classical phenomenological models for composite materials (like concrete). The model is constructed from fine scales by making use of the corresponding meso-scale representation of concrete distinguishing aggregate from cement paste. The elastic response and failure mechanisms at this scale are represented by the corresponding unstructured mesh of truss elements, which is shown to be capable of representing a number of fine features of inelastic response, such as the statistical isotropy of elastic response placed in- between the stringent Hashin-Shtrikman bounds, the pronounced difference of behavior in tension and compression, the sensitivity of bi-axial compression strength to the volume fraction of aggregate and the bi-axial fracture energy corresponding to each particular mode of failure. The results of this kind obtained with meso-model are then packed within a new meso-scale model with these enhanced features, which can be used to replace the standard phenomenological models of concrete.
\end{abstract}

Keywords: heterogeneous materials, meso-scale model, failure surface, embedded discontinuity, biaxial loading

\section{Introduction}

The non-linear analysis of structural components working under complex loading program is nowadays an indispensable ingredient of a performance based design. Given this

Email address: benkemoun@lmt.ens-cachan.fr (N. Benkemoun, J.-B. Colliat and A. Ibrahimbegovic) Preprint submitted to Elsevier

October 14, 2016 
current trend, it has become crucial to have accurate tools that improve the predictive capabilities of macroscopic constitutive equations and furnish a precise description of nonlinear response in structural analysis. At the structural scale, phenomenological models based on macroscopic quantities such as macroscopic stresses and strains and macroscopic laws placed in the thermodynamical framework are widely used. Considering cement-based materials such as concrete, there is an extensive literature [1] dealing with its phenomenological constitutive behavior modelling ([2], [3]) according to different loading paths, for static or dynamical cases as well as several multi-physics coupling. However, because of their macroscopic nature, these models present difficulties in describing correctly the physical mechanisms (fracture, damage and transport mechanisms) taking place at finer scales and involving macroscopic observations. Moreover in the case of a complex loading program (e.g. non-proportional loading) they require to properly choose the criterion to use in relation with the studied material and the applied loading. This can lead to substantial difficulties when devising a successful identification procedure ([4]) which would allow to obtain the correct range of all the model parameters. So, their predictive capability is rather limited for very different loading programs with respect to the one which was used in identification. That is why the main goal of this paper is to provide a novel version of a phenomenological constitutive anisotropic model for concrete based upon information coming from finer scales and the corresponding numerical testing. Namely, we first seek to quantify correspondingly the difference in behavior in tension and in compression, as well as the fracture energy accompanying each of different modes of failure. Second, we carry out large number of numerical tests to master the inelastic mechanism's evolution from finer scales and very different loading programs. The resulting constitutive model we propose on numerical testing can be considered as the most appropriate combination of multi-surface models for concrete combining Drucker-Prager for compression stress and Rankine for tensile stress [5] with a damage model describing the localized failure of structure ([6], [4]). The combination is not done in ad-hoc way, but constructed in accordance with a meso-scale representation of concrete distinguishing aggregates and cement paste [7] and the result of computations corresponding to the chosen loading program. Therefore, the proposed model 
can account for several fine scale imprints such as compressive strength increase as a function of aggregate volume fraction or the fracture energy typical of failure mode. In this manner, we obtain a model capable of describing different failure modes, including the phenomena of localized failure which is of great interest for performance based design. This is also the main novelty of our present approach with relation to [7] and [6], we now replace a meso-scale model by an equivalent macro-scale model where failure criteria parameters depend directly of meso-scale computations.

The outline of this paper is as follows. In Section 2, we give a brief description of the meso-scale model of concrete first developed in [7] which is adapted to the present goal. In Section 3, we turn to providing a detailed description of a failure surface obtained with meso-scale model computations.

\section{Meso-scale model for failure analysis of two-phase quasi-brittle material}

In this section, we give a brief description of the meso-model of a typical two-phase composite material, such as concrete. For the readers interested in more details, a complete description of the model, its numerical implementation and a number of illustrative examples of the model predictive capabilities can be found in [7].

\subsection{Meso-model features}

The numerical tool in [7] is based upon a two-phase (aggregates melt into a mortar matrix) quasi-brittle finite element model capable of representing the behavior of concretelike materials under complex loading paths. In order to take into account the influence of the shape, the size, the distribution and the mechanical properties of aggregates on the mechanical behavior of concrete, the meso-scale is chosen to be the scale of computation. This scale has been utilized by others researchers to account for heterogeneities in materials such as concrete [8] and soils [9]. The meso-scale we work with to model two-phases quasibrittle material is based upon a 3D lattice finite element model [10], [11], [12] and [13] whose truss elements kinematics is enhanced by two discontinuities. 
The first discontinuity is based upon a weak discontinuity (continuous displacement field and discontinuous strain field) [14]. It is introduced because of the retained meshing process which relies on non-conforming mesh [15] where some truss elements are cut into two parts, each having different elastic properties. Considering a two-phase material example in 2D (Fig. 1(a) with the mortar matrix in blue, one aggregate in green and the interface in red, the finite element discretization gives three sets of truss elements (Fig. 1(b)): those entirely inside the matrix (in blue) with no weak discontinuity activated, those entirely in the aggregate (in green) with no weak discontinuity activated and those split by a physical interface (in bold red) for which the weak discontinuity is activated. Non-conforming meshes provide the advantage to have a meshing process independent from the microstructure (positions of the aggregates and shapes), as well as the fixed size of the mesh in probability studies [14] of meso-structure for this kind of material.

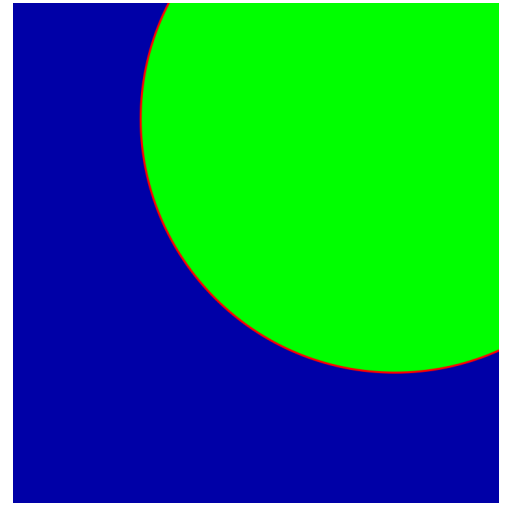

(a) Aggregate melt into a mortar matrix

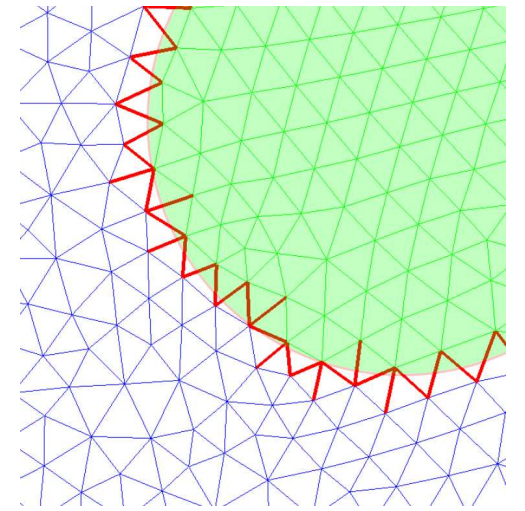

(b) FE discretization

Figure 1: 2D discretization with a non-conforming mesh

In the present work, this approach is applied to three dimensional domains. Fig. 2 represents a $0.1 \mathrm{~m} \times 0.1 \mathrm{~m} \times 0.1 \mathrm{~m}$ cube with $30 \%$ of aggregates. We find again in blue the mortar matrix, in green the aggregates and in red the interfaces.

The second discontinuity relies upon a strong discontinuity (discontinuous displacement field and unbounded strain field) [16], [17], [18]. It is introduced in order to represent micro-cracks that may occur in any of different phases (aggregates or mortar matrix for 


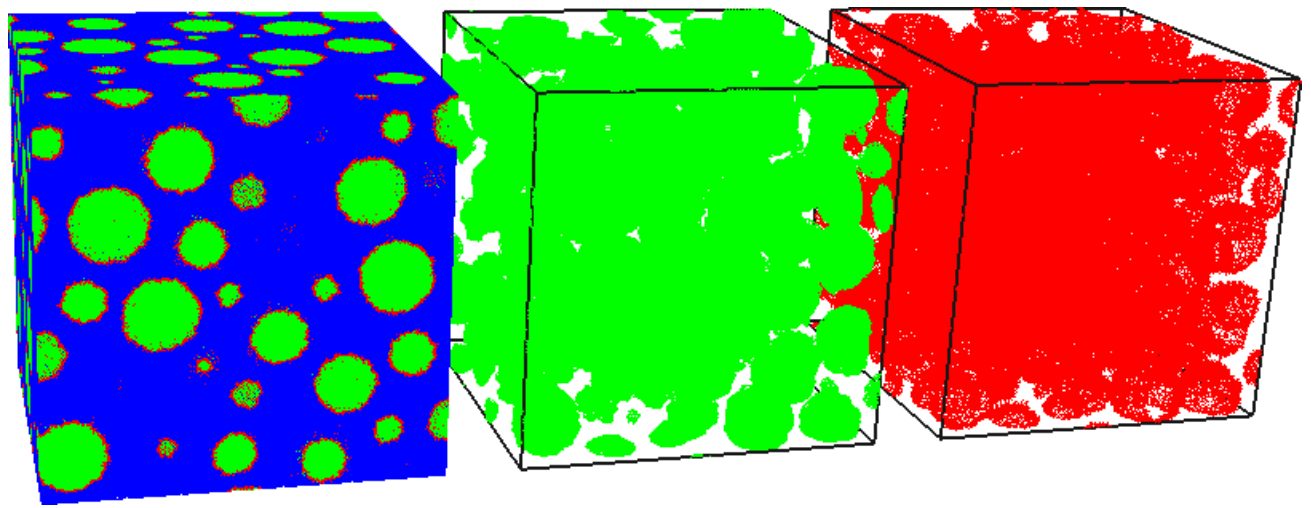

Figure 2: 3D domain for a typical two phases material: mortar matrix blue, aggregates green, red interfaces

two-phase materials) and to capture the interface failure (debonding). Moreover, the key point pertains to strong discontinuities capability to model softening behavior without any mesh dependency [16], [19] which is the major issue dealing with failure of quasi-brittle materials.

The weak discontinuity is present only for the truss elements split into two parts, each having a different Young modulus. The strong discontinuity is introduced by means of a yield function $\Phi$ which is triggered only in traction. Thus two constitutive models appear for a truss element : a continuum one (outside the discontinuity : Fig. 3(a)), which is elastic, and a discrete one (at the discontinuity : Fig. 3(b) which is quasi-brittle. This approach is called the "Discrete Strong Discontinuity Approach" and can be found in [20]. We denote with $t_{\Gamma}$ the traction vector at the discontinuity and with $[|u|]$ the crack opening.

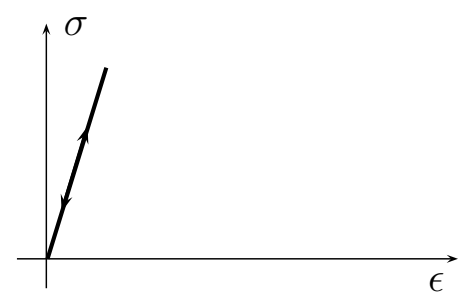

(a) behavior outside the discontinuity

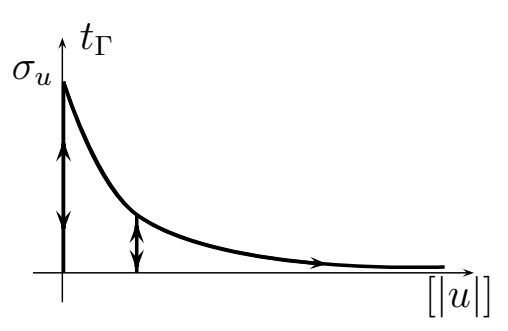

(b) behavior at the discontinuity

Figure 3: Elastic-quasi-brittle behavior

For the discrete model, the softening law is introduced in terms of the internal variable 
$q$ by considering the exponential form,

$$
q=\mathrm{k}([|u|]) ; \mathrm{k}([|u|])=\sigma_{u}\left(1-\exp \left(-[|u|] \frac{\sigma_{u}}{G_{f}}\right)\right)
$$

The latter appears in the yield function which can be written as

$$
\Phi=t_{\Gamma}-\left(\sigma_{u}-q\right)
$$

In summary, there are altogether eight model parameters:

1. the Young modulus $E_{1}$ for the mortar matrix and $E_{2}$ for aggregates for the continuum model,

2. the ultimate tensile strength before softening, $\sigma_{u_{i}}$ and the fracture energy, $G_{f_{i}}(i=$ 1, 2, 3 for respectively the mortar matrix, aggregates and interfaces) for the discrete model. We note that $G_{f_{i}}$ as the area under the curve $t_{\Gamma}-[|u|]$.

The mathematical framework for the introduction of these discontinuities in a finite element problem is the Hu-Washizu [21] three fields variational formulation discretized by using the Incompatible Modes method [22], [23]. Among the different possibilities [24], 25] to discretized the deformation field, the "Enhanced Finite Element Method" (E-FEM) [26] has been chosen. Practically, this means that the deformation field is enhanced by two functions : $G_{1}^{(1 / 2)}$ and $G_{2}$. The first one is a weak discontinuity, introduced as a piecewise linear function over an element capturing the jump of the Young modulus in the deformation field. The second one is split into a constant function and a Dirac function capturing the unbounded nature of the strain field in presence of a strong discontinuity. One can observe these functions on Fig. 4 and Fig. 5 thanks to a zoom on a interface truss element (red bold elements on Fig. 1(b) and Fig. 2).

This kind of discretization leads to the following system of equations to be solved :

$$
\begin{cases}\mathbf{A}_{e=1}^{n_{\text {elm }}}\left[\mathbf{f}_{e}^{i n t}(\boldsymbol{d},[|u|],[|\epsilon|])-\mathbf{f}_{e}^{e x t}\right]=\mathbf{0} & \\ -\sigma_{1}(\boldsymbol{d},[|u|],[|\epsilon|])+\sigma_{2}(\boldsymbol{d},[|u|],[|\epsilon|])=0 & \forall e \in\left[1, n_{\text {elm }}\right] \\ \theta \sigma_{1}(\boldsymbol{d},[|u|],[|\epsilon|])+(1-\theta) \sigma_{2}(\boldsymbol{d},[|u|],[|\epsilon|])-t_{\Gamma}=0 & \forall e \in\left[1, n_{\text {elm }}\right] \\ t_{\Gamma}-\left(\sigma_{u}-q\right)=0 & \forall e \in\left[1, n_{\text {elm }}\right]\end{cases}
$$




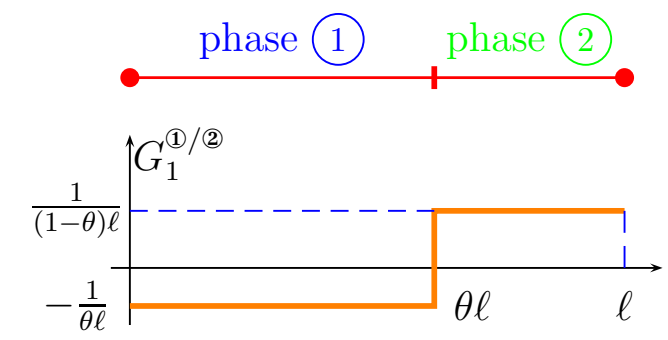

Figure 4: Enhanced deformation field for a two-phase truss element

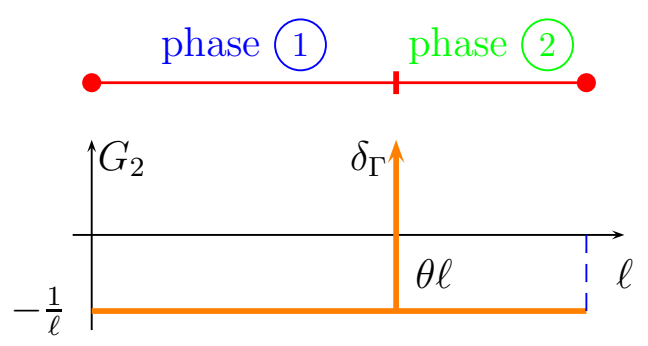

Figure 5: Enhanced deformation field for a quasi-brittle truss element 
where A denotes the standard assembly operator ([27], [28]).

The first equation is the classical global equilibrium obtained for a finite element problem. The second and the third ones are respectively the local equilibrium concerning the weak discontinuity enhancement and the strong discontinuity enhancement. Both are written in function of $\sigma_{1}$ and $\sigma_{2}$ which are the stresses in each subdomain of the element and $t_{\Gamma}$, the traction vector at the discontinuity. We recall that the scalar value $\theta$ parameterizes the discontinuity spatial position. In $(3)$, $[|u|]$ and $[|\epsilon|]$ are the interpolation parameters corresponding to both strong and weak discontinuities. Note that $[|u|]$ is nothing but the crack opening. These two parameters are defined independently for each element so that they are local quantities only. It is important to note that only the second equation of (3) is a linear equation. Moreover, the strong discontinuity is introduced only upon reaching a fracture criterion, so that the third and fourth equations in system (3) are not always present. Computational procedure used to obtain the solution of (3) is explained in details in [7].

\subsection{Illustrative validation examples}

In this subsection, we present several illustrative examples and predictive features of the meso-scale model.

\subsubsection{Exact solution of a $1 D$ problem with weak discontinuity}

This first validation concerns the ability of the function $G_{1}^{(\mathbb{1} /(2)}$ to represent a finite jump in the deformation field (weak discontinuity) and the accuracy of the incremental value $\Delta[|\epsilon|]^{(k+1)}$ computation.

Consider a bi-material bar $\left(\Omega=\Omega_{1} \cup \Omega_{2}\right)$ of length $l=2$ with material modulus $E_{1}$ in $\Omega_{1}$ and with $E_{2}$ in $\Omega_{2}$, where $\Omega_{1}=\left(-1, \theta l^{e}\right)$ and $\Omega_{2}=\left(\theta l^{e}, 1\right)$. The interface $\Gamma$ is located at $\mathrm{x}=\theta l^{e}$ where $l^{e}$ is the length of one finite element. For the pure Dirichlet problem, with $u$ $=0$ at $x=-1, u=1$ at $x=1$, and no body forces, the exact displacement solution is given 
in [29] by :

$$
u(x)=\left\{\begin{array}{r}
(1+x) \alpha,-1 \leq x \leq \theta l^{e}, \\
1+\frac{E_{1}}{E_{2}}(x-1) \alpha, \theta l^{e} \leq x \leq 1,
\end{array}\right.
$$

where

$$
\alpha=\frac{E_{2}}{E_{2}\left(1+\theta l^{e}\right)-E_{1}\left(\theta l^{e}-1\right)} .
$$

In this example, $E_{1}=5 \mathrm{MPa}$ and $E_{2}=10 \mathrm{MPa}$. Numerical results are computed for a bar discretized with a structured mesh containing 20 finite elements with three different locations of the interface : $\theta l^{e}=0.0025,0.05$ et 0.075 . In Fig. 6, the finite element mesh and the interface are shown for $\theta l^{e}=0.05$. The numerical results for the relative error in

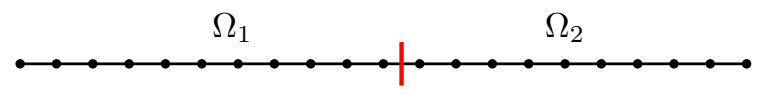

Figure 6: Bi-material bar problem : mesh and interface position for $\theta l^{e}=0.05$

the energy norm are presented in Tab. 1. The relative error in the energy norm is chosen as :

$$
e=\int_{\Omega}\left(\epsilon-\epsilon^{h}\right) E\left(\epsilon-\epsilon^{h}\right) d \Omega
$$

where $\epsilon$ and $\epsilon^{h}$ are respectively the deformation obtained thanks to the exact solution (4) and the deformation obtained with the finite element computation. $E$ is the Young modulus depending on the position $x$.

\begin{tabular}{|c|c|}
\hline Interface location $\xi$ & Relative error in the energy norm \\
\hline 0.0025 & $1.3 \times 10^{-10}$ \\
0.05 & $3.12 \times 10^{-10}$ \\
0.075 & $3.18 \times 10^{-10}$ \\
\hline
\end{tabular}

Table 1: Relative error in the energy norm for the bi-material bar problem

By analyzing the numerical results (Tab. 1, Fig. 7 et Fig. 8), one can note that the function $G_{1}^{(1 / 2)}$ is the appropriate enrichment function to capture the jump in the Young 
modulus values at the interface $\theta l^{e}$. This was reasonable to expect because we sought to preserve the equivalence between the structured mesh with E-FEM space and the exact mesh with standard FEM space in which the interface coincides with a node. Namely, our results are capable of reproducing the piecewise linear nature of the exact solution (4) thanks to the chosen enrichment function which is piecewise linear.

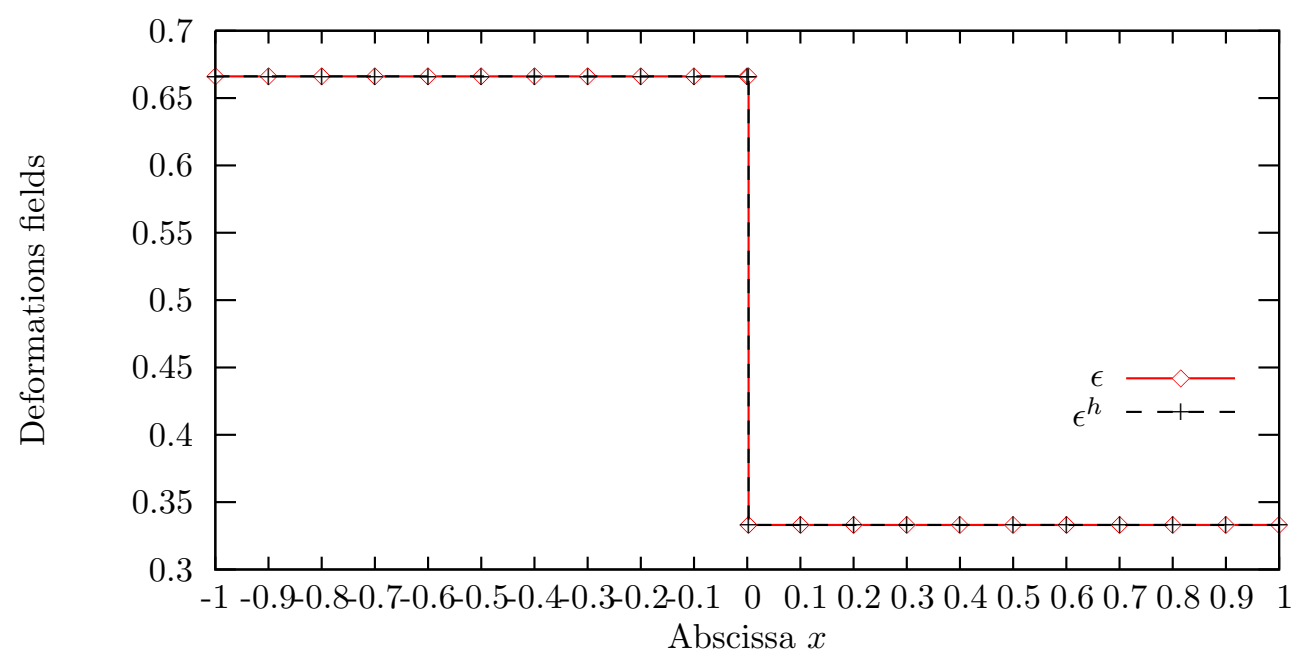

Figure 7: Exact and computed deformations fields for $\theta l^{e}=0.0025$

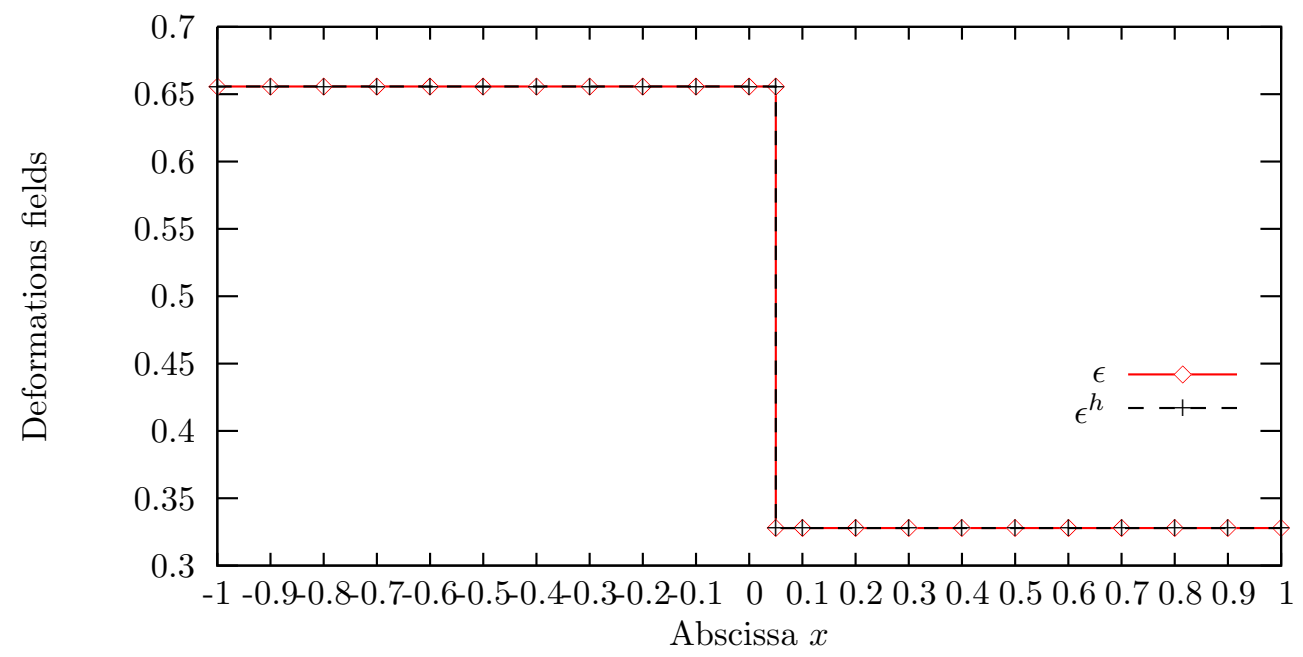

Figure 8: Exact and computed deformations fields for $\theta l^{e}=0.05$ 


\subsubsection{Classical homogenization : comparison with Hashin-Shtrikman bounds for 3D case}

In this example, we turn now to a weak discontinuity validation in three dimensions by exploring the Hashin-Shtrikman bounds.

At meso-scale for real concrete, we assume that the aggregates embedded in the mortar matrix exhibit an isotropic behavior because of their sizes and the material processing technique. In order to validate the meshing technique with non-conforming mesh used to represent two-phase material with aggregates embedded in a mortar matrix at meso scale, we rely upon the variational principle of Hashin and Shtrikman [30]. This variational principle provides bounds for the effective properties of a composite that are in general more strict than the classical upper bound of Voigt and lower bound of Reuss [31]. These bounds are sensitive to specimen size and are strictly valid only when the body is assumed to be infinite, the microstructure isotropic and the effective responses are isotropic. The RVE used for the numerical analysis is a $0.1 \mathrm{~m} \times 0.1 \mathrm{~m} \times 0.1 \mathrm{~m}$ cube made of spherical aggregates melt into a mortar matrix. The aggregates size is ranging from 3 to $19 \mathrm{~mm}$ of diameter. Displacement boundary conditions are applied at the boundaries of this cube. On the face $\mathrm{X}=0.1 \mathrm{~m}$, a displacement of $10^{-5} \mathrm{~m}$ is imposed in the $\mathrm{X}$ direction and faces $\mathrm{X}=0 \mathrm{~m}, \mathrm{Y}=0 \mathrm{~m}$ and $\mathrm{Z}$ $=0 \mathrm{~m}$ are restrained respectively in the $\mathrm{X}, \mathrm{Y}$ and $\mathrm{Z}$ directions. Tab. 2.2.2 gives the material data of the mortar matrix and aggregates and the effective Young modulus computed from the numerical simulations. Fig. 2.2.2 represents the effective Young modulus for the finite element model and its 3D Hashin-Shtrikman bounds for a volume fraction of aggregates ranging from 0 to $45 \%$. One can observe that the finite element model response is in-between Hashin-Shtrikman bounds, in spite of the fact that the sample is not of infinitely large size. This confirms its ability to correctly represent isotropic two-phases material by the chosen non-conforming mesh.

\subsubsection{Mesh objectivity of computed response in localized failure}

In this subsection, a strong discontinuity approach validation is proposed by exploring the mesh objectivity with respect to any choice of finite element discretization.

In order to illustrate the mesh objectivity in relation with the finite element discretiza- 


\begin{tabular}{lccc}
\hline Material type & $\begin{array}{c}\text { Material properties } \\
E(G P a)\end{array}$ & Volume fraction (\%) & $\begin{array}{c}\text { Numerical Young modulus } \\
E(G P a)\end{array}$ \\
\hline Cement paste & 10 & 6 & 11.153 \\
& & 15 & 13.617 \\
& 20 & 15.147 \\
Aggregate & 30 & 17.923 \\
& 70 & 40 & 21.532 \\
\hline
\end{tabular}

Table 2: Material data of constituents

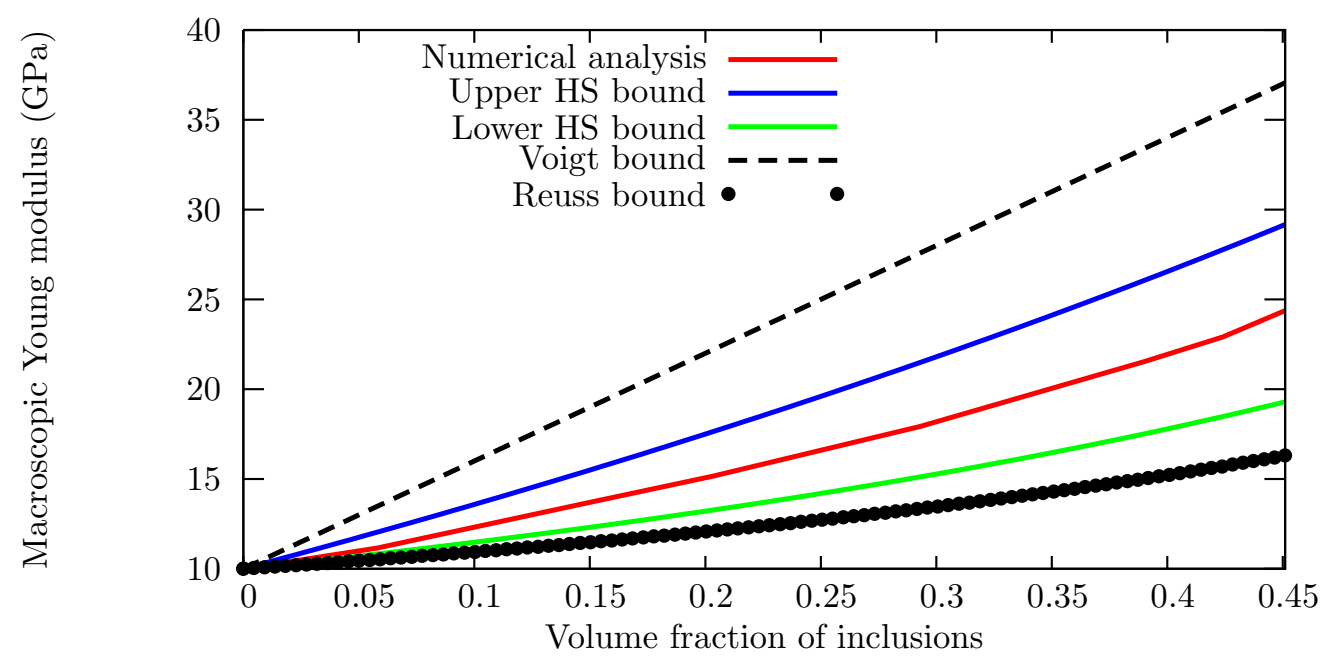

Figure 9: Hashin-Shtrikman, Voigt and Reuss bounds 
tion, a tension specimen is analyzed by using two different meshes with 260000 and 690000 elements. The specimen is a $0.1 \mathrm{~m} \times 0.1 \mathrm{~m} \times 0.1 \mathrm{~m}$ homogeneous cube discretized by the 3D lattice model introduced previously. This cube is then composed of truss elements, with quasi-brittle behavior presented in Fig. 3. On each facette $\mathrm{X}=0 \mathrm{~m}, \mathrm{Y}=0 \mathrm{~m}$ and $\mathrm{Z}=0 \mathrm{~m}$, the cube is restrained in the $\mathrm{X}, \mathrm{Y}$ and $\mathrm{Z}$ directions, respectively. On the facette $\mathrm{X}=0.1 \mathrm{~m}$, a displacement is imposed in $\mathrm{X}$ direction. For the purpose of fixing the localization zone, the elements in the plane $\mathrm{X}=0.05 \mathrm{~m}$ are weakened with a reduction of $1 \%$ in the ultimate tensile strength.

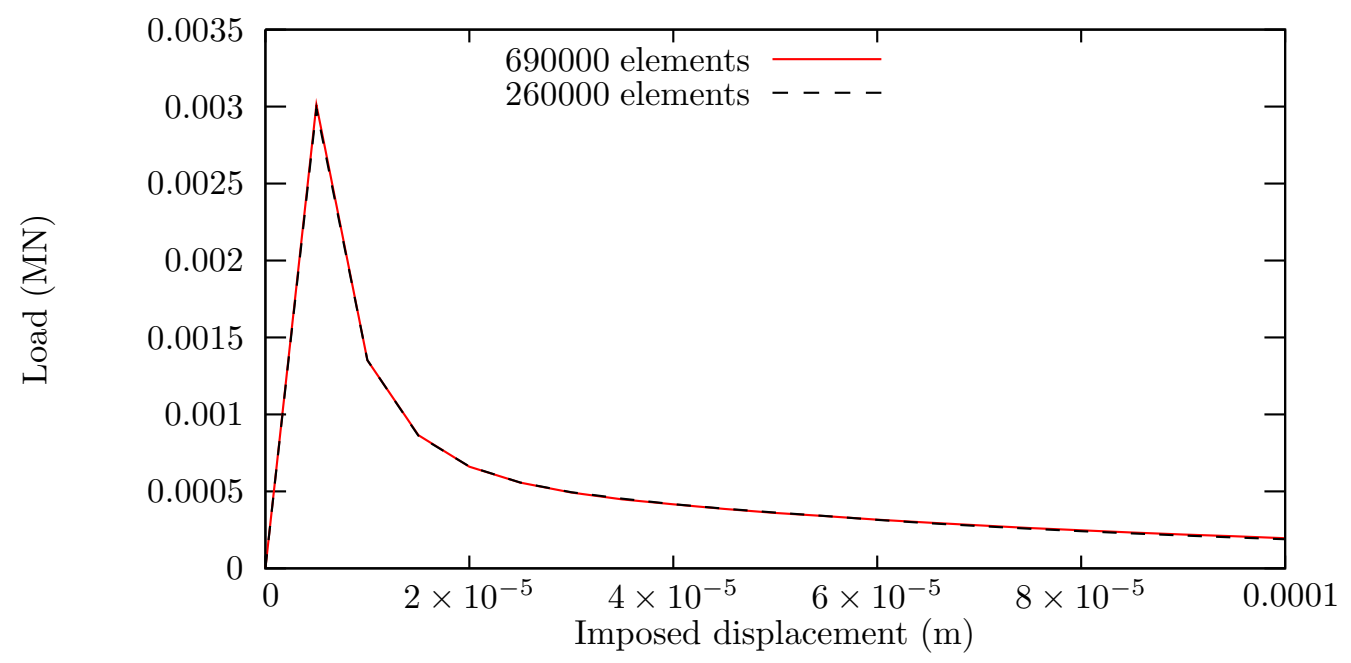

Figure 10: Load-imposed displacement for different finite element discretization

The load-imposed displacement response computed for two meshes is shown in Fig. 10. It can readily be seen that the global response is independent from the chosen mesh discretization. Indeed the dissipated energy during the loading program is the same whatever the number (and the size) of chosen elements. One can observe in Fig. 11 the computed displacement field at the end of the computation which is nearly identical for the two meshes. Moreover, Fig. 12 shows values of displacement discontinuity or crack opening in the broken elements at the end of the computation which is again identical for the two meshes. 


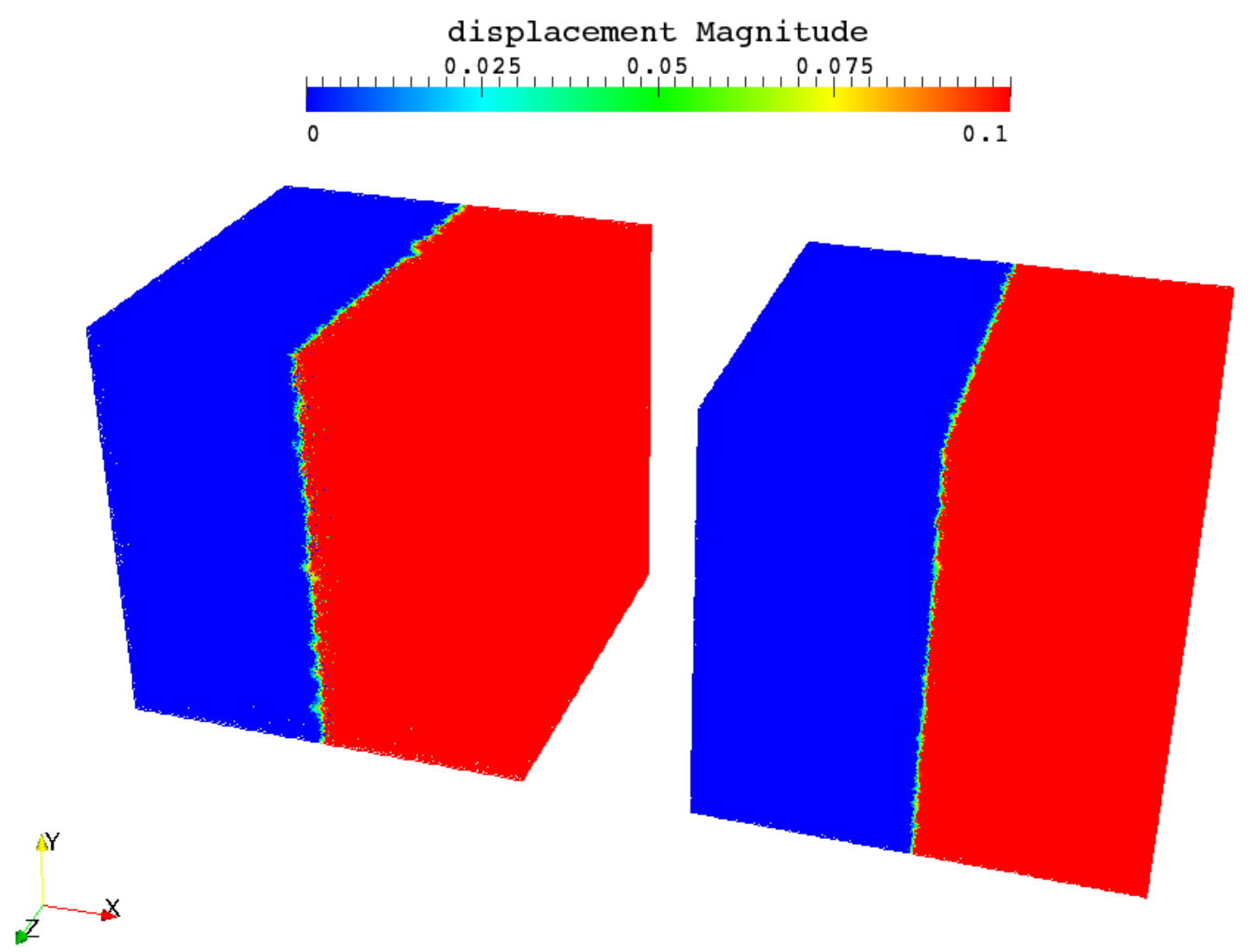

Figure 11: Displacement magnitude at the end of the computation: a) 260000 elements, b) 690000 elements 


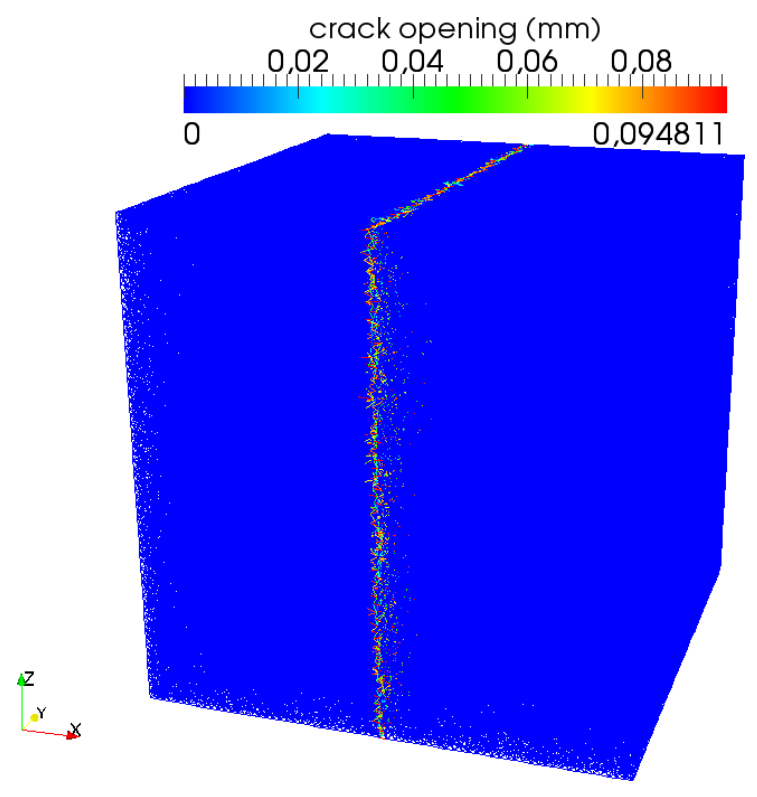

(a) 260000 elements

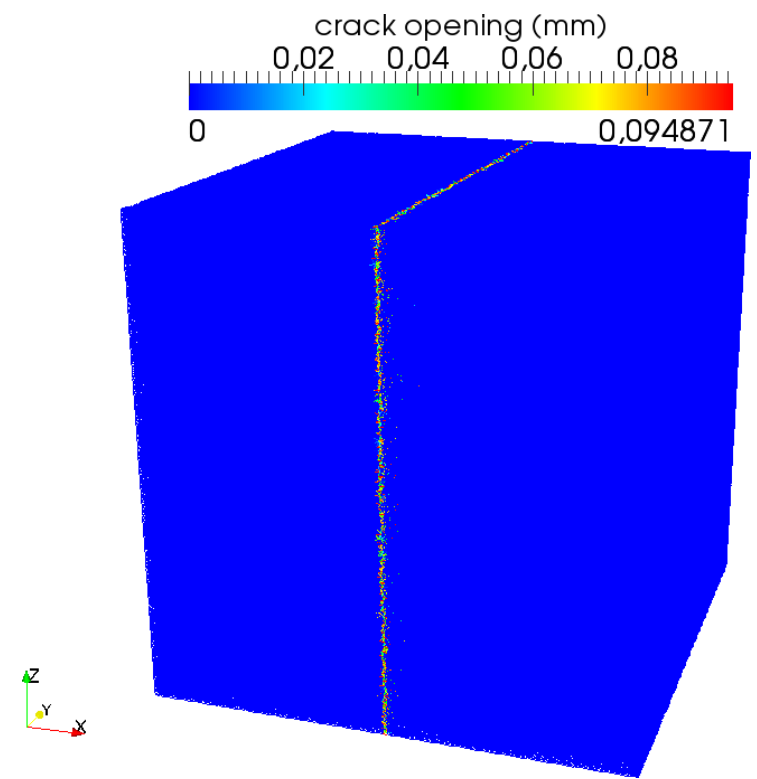

(b) 690000 elements

Figure 12: Crack opening at the end of the computation 


\subsection{4. $1 D$ diagrams for different volume fraction}

This subsection presents an example that illustrates the model capability to represent failure mechanisms for concrete-like materials.

In order to illustrate the capability of the model to represent failure mechanisms for concrete-like materials, we present two numerical simulations. The first one is a tension test and the second is the standard compression test. The specimen is $0.1 \mathrm{~m} \times 0.1 \mathrm{~m} \times$ $0.1 \mathrm{~m}$ cube with 24, 35 and $45 \%$ of aggregates. Fig. 13 shows the response obtained both in tension and compression. One can observe a significant difference of behavior in tension and compression, which is one of the major characteristics related to quasi-brittle materials like concrete. Both the peak stresses as well as the amount of dissipated energy are much greater in compression than in tension. Moreover, it is important to observe the key role of aggregates in compression : a higher percent of aggregates tend to rise up the ultimate strength whereas in tension the ultimate strength is quasi-independent of this percentage increase (Fig. 13).

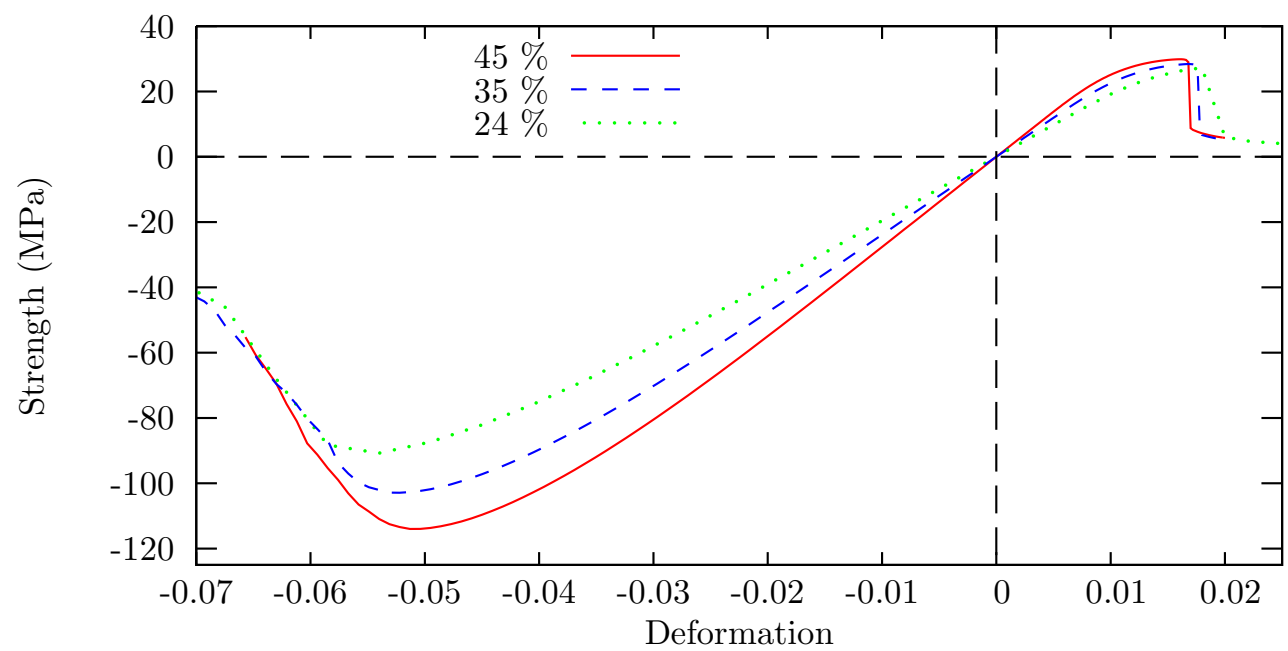

Figure 13: Macroscopic response in tension/compression

\section{Failure surfaces}

In this Section, we show how to use this meso-scale model, in order to provide an original approach to obtain a failure surface taking into account heterogeneities and different process 
of cracking.

\subsection{Literature review on failure surfaces}

The failure surfaces proposed in the literature for a concrete-like material are generally based upon phenomenological models ([5], [32], [33], [34] and [1]). The models of this kind rely upon a rigorous thermodynamics framework [27], which is very well adapted to structural computation. Nevertheless, they require to properly identify and determine model parameters in relation with the studied material and the applied loading program. Thus the choice of model parameters must be made with a consistent calibration procedure (e.g. see [4]). In the case of a failure surface, this should include the calibration of the initial yield and damage surfaces that are in accordance with experiments, along with other parameters governing the evolutions of these surfaces. Moreover, because of their macroscopic nature, these models present difficulties in taking into account explicitly heterogeneities (e.g. aggregate shape, distribution, sizes and behavior) as well as the corresponding information at finer scales, which plays a fundamental role $([35])$ in most of the physical phenomena observed at the macroscopic scale. In addition, in order to describe correctly physical mechanisms (as failure mechanisms, for example) taking place at finer scales and responsible of macroscopic observations, phenomenological models require again the identification of several parameters $([36])$ and remain of fairly limited predictive capabilities outside of the given loading program.

That is why in this section, a new approach is presented: the coupling between the fine scale, here chosen as the meso-scale, where the quasi-brittle behavior is introduced, with the macroscopic scale, where the failure surface is obtained by the numerical computation of ultimate strength, is done naturally. Namely, every points of the surface take into account failure mechanisms taking place at the fine scale and the material heterogeneity. In this sense, a novel version of a phenomenological constitutive anisotropic model for concrete based upon information coming from finer scales is obtained. The proposed model can approximately be considered as the most appropriate combination of multi-surface models for concrete combining Drucker-Prager for compression stress and Rankine for tensile stress 
[5] with a damage model describing the localized failure of structure ([6], [4]). However, contrary to this classical combination, the proposed model can also provide the compressive strength related to the volume fraction, as well as the fracture energy corresponding to each particular failure mode.

\subsection{Numerical loading program}

In order to examine the ability of the Finite Element model to provide biaxial failure behavior characteristic of a heterogeneous material specimen, three concrete specimens with a plate form of $100 \mathrm{~mm} \times 100 \mathrm{~mm} \times 10 \mathrm{~mm}$ (Fig. 14) and a different volume fraction of aggregates (Table 3) were subjected to biaxial imposed displacements, producing the following stress combinations : compression-compression, tension-tension, compression-tension and tension-compression. Their uniaxial compressive strength values $\sigma_{c_{i}}(\mathrm{i}=1,2,3)$ were taken from a uniaxial compressive test performed on each concrete specimens.

\begin{tabular}{cccc}
\hline Specimen $i$ & Volume fraction $f_{i}(\%)$ & Uniaxial compressive & Size aggregates range \\
& & strength $\sigma_{c_{i}}(M P a)$ & $(\mathrm{mm})$ \\
\hline 1 & 15 & 8.7 & $2.4-19$ \\
2 & 35 & 9.5 & $2.4-19$ \\
3 & 40 & 11 & $2.4-19$ \\
\hline
\end{tabular}

Table 3: Specimen data

In order to numerically cover the four regions (compression-compression, tension-tension, compression-tension and tension-compression), a circular loading program based upon the trigonometrical circle $\cos (\alpha)^{2}+\sin (\alpha)^{2}=1$ was performed. This leads to couples of imposed displacements $\left(\mathrm{u}_{1}=\cos (\alpha), \mathrm{u}_{2}=\sin (\alpha)\right)$ parameterized by the angle $\alpha$. Displacements $\mathrm{u}_{1}$ and $\mathrm{u}_{2}$ are respectively applied to faces $\mathrm{X}=100 \mathrm{~mm}$ and $\mathrm{Y}=100 \mathrm{~mm}$. Faces $\mathrm{X}=0 \mathrm{~mm}$, $\mathrm{Y}=0 \mathrm{~mm}$ and $\mathrm{Z}=0 \mathrm{~mm}$ are respectively blocked in $\mathrm{X}, \mathrm{Y}$ and $\mathrm{Z}$ directions (Fig. 15). Tension is chosen as positive. Stress in the principal direction 1 (X direction) is called $\sigma_{1}$, the one in the principal direction 2 (Y direction) $\sigma_{2}$. In addition, the ultimate strength in the principal direction 1 is written $\bar{\sigma}_{1}$ and the one in the direction $2, \bar{\sigma}_{2}$. 


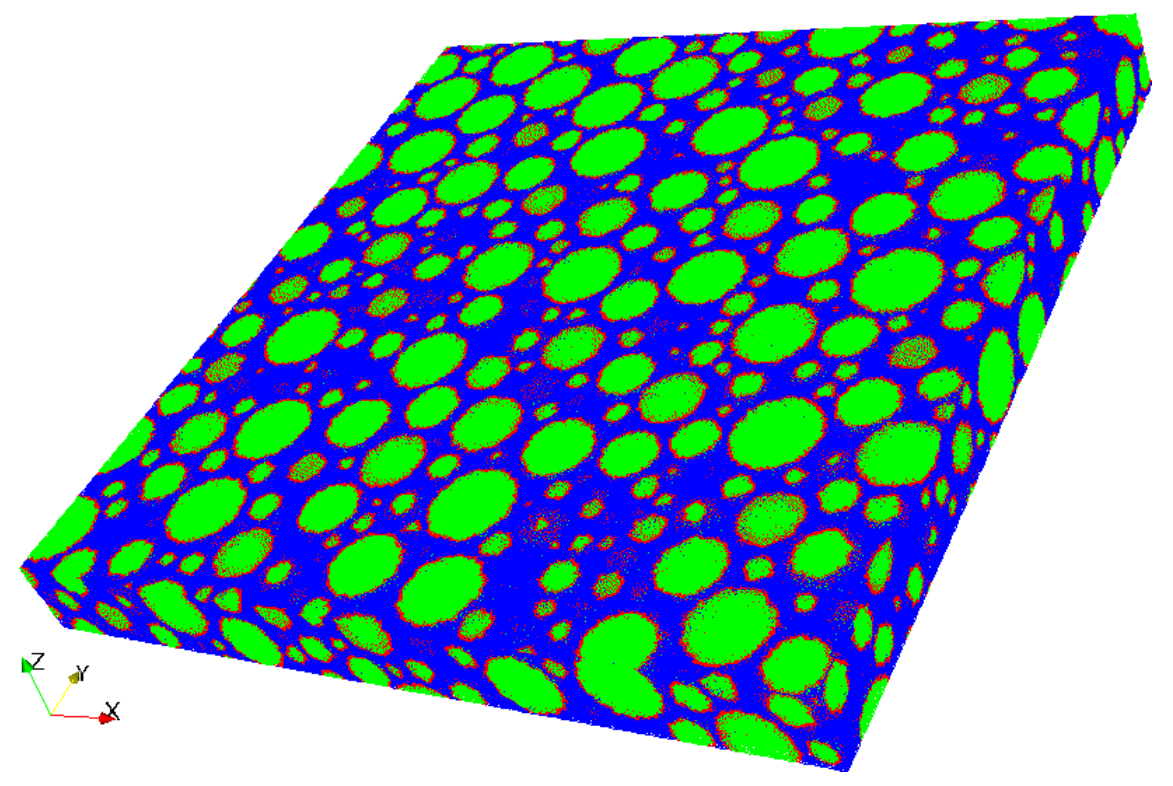

Figure 14: Specimen and microstructure with $40 \%$ of aggregates

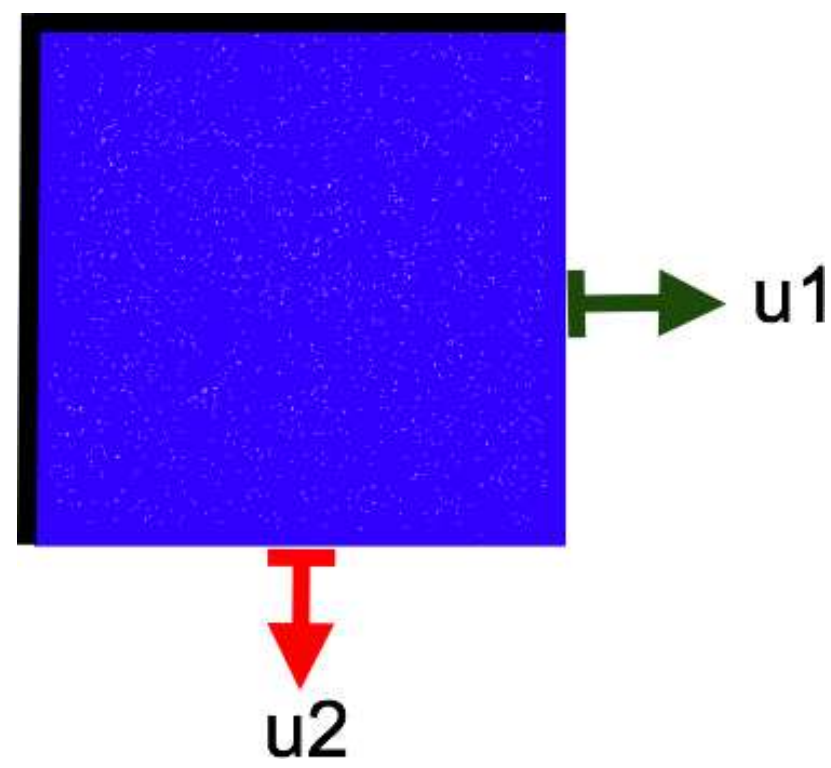

Figure 15: Specimen boundaries conditions and loading 
Tables 4 and 5 provide ratio of ultimate strength $\bar{\sigma}_{1}$ and $\bar{\sigma}_{2}$ with respect to $\sigma_{c_{2}}$ under different couples of imposed displacements for 15,35 and $40 \%$ of aggregates. Tables 6 give the fracture energy under particular couples of imposed displacements for 15, 35 and 40 $\%$ of aggregates. Fig. [16 is a graphical representation of the relationship between $\bar{\sigma}_{1} / \sigma_{c_{2}}$ and $\bar{\sigma}_{2} / \sigma_{c_{2}}$ for 15,35 and $40 \%$ of aggregates. In the same spirit of Yield surfaces, those representations are referred to as failure surfaces. Fig. 16 stresses several characteristics of the concrete behavior under biaxial solicitations.

First, one can note that we find again the symmetrical behavior of concrete in relation with the $45^{\circ}$ line under biaxial loading observed in experimental approaches ([37]) whatever is the volume fraction of inclusions. One can observe that the ultimate strength of concrete under biaxial compression is higher than the one under uniaxial compression. Physically this is due to the increased confinement for biaxial compression. It is important to notice that for the region of compression-compression, the strength increase for each specimen in relation to their uniaxial compressive strength $\sigma_{c_{i}}(\mathrm{i}=1,2,3)$ is dependant of the couple of imposed displacements, the maximum biaxial strength being for $\left(\mathrm{u}_{1}=-0.015 \mathrm{~mm}\right)$ and $\left(\mathrm{u}_{2}=-0.058\right.$ $\mathrm{mm}$ ) (with an relative average increase of $42 \%$ for $f=15 \%, 34 \%$ for $f=35 \%$ and $16 \%$ for $f=40 \%$ ) whereas for the region of tension-tension, the value of the concrete ultimate strength for each specimen is quasi independent of the couple of imposed displacements and is very close to the uniaxial tensile strength whatever the volume fraction is. At equal biaxial compression $\left(\mathrm{u}_{1}=-0.06 \mathrm{~mm}\right.$ and $\left.\mathrm{u}_{2}=-0.06 \mathrm{~mm}\right)$, the relative average strength increase in relation to uniaxial compression strength is $5 \%$ for $f=15 \%, 10 \%$ for $f=35 \%$ and $4 \%$ for $f=40 \%$. Then, one can notice the key role of the volume fraction of aggregates in the behavior of concrete under biaxial loading: in the region of compression-compression a higher percentage of inclusions tends to rise up noticeably the ultimate strength and the fracture energy whereas in the three others regions the ultimate strength and the fracture energy are quasi independent of volume fraction.

Finally, in the region of tension-compression, the value of the ultimate strength decreases in compression when the one in tension increases. In general, the failure pattern is perpendicular to the principal tension direction. Most of these tendencies described in this part 
are consistent with experimental results of [38], [39] and [40].

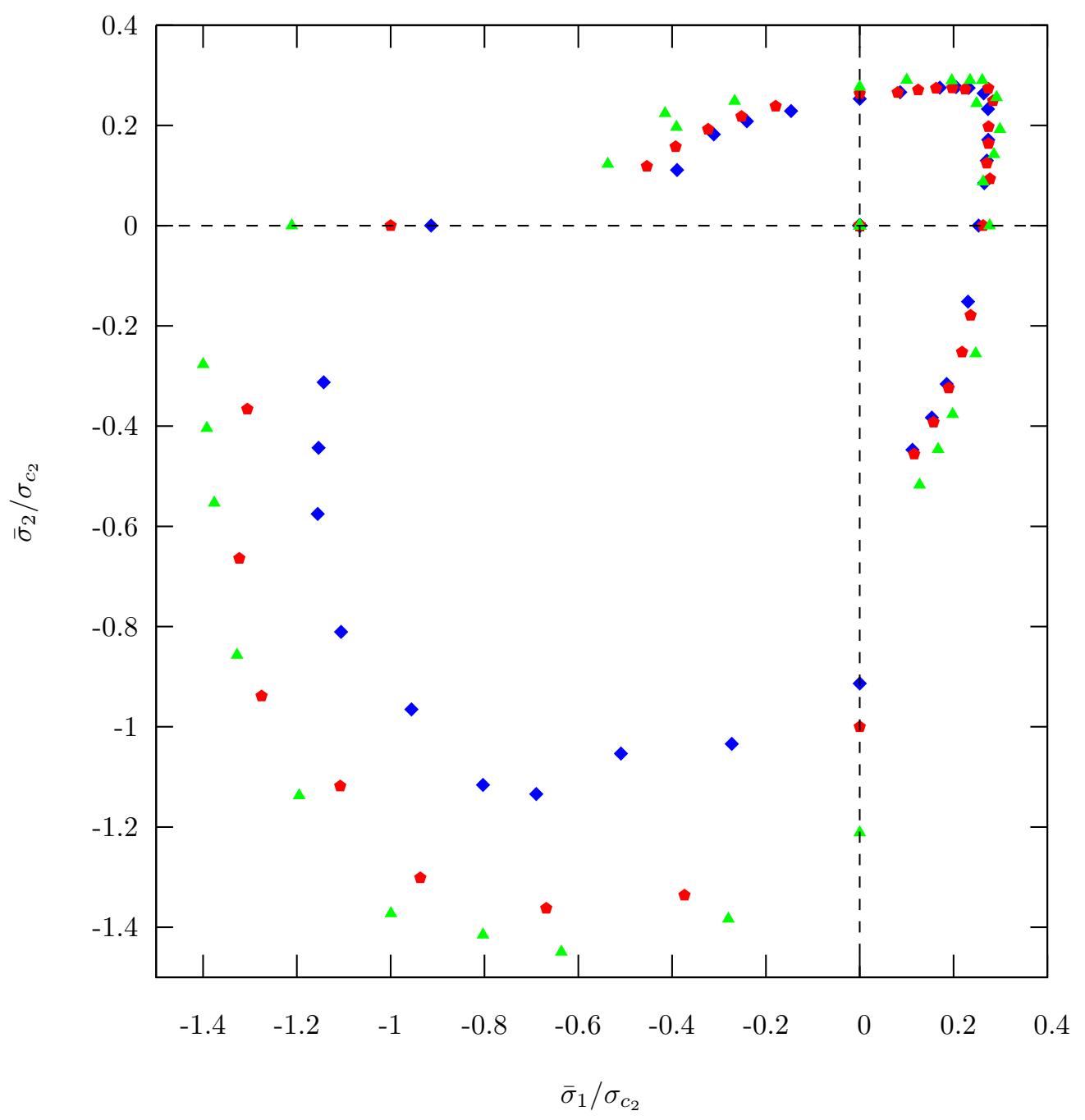

Figure 16: Failure surfaces for $15 \%$ (diamond), $35 \%$ (pentagon) and $40 \%$ (triangle) of aggregates

Fig. 17 represents the evolution, during the loading, of the ratio $\bar{\sigma}_{1} / \sigma_{c_{2}}$ in relation with $\bar{\sigma}_{2} / \sigma_{c_{2}}$ for the case of $40 \%$ of inclusions. In green, are shown the points corresponding to the green points of Fig. 16.

For the regions of tension-tension, compression-tension and tension-compression, two phases of computed response can be observed. The first one corresponding to a linear relation between $\bar{\sigma}_{1} / \sigma_{c_{2}}$ and $\bar{\sigma}_{2} / \sigma_{c_{2}}$ : cracking is not very present (few elements are broken) so a linear relation between the two ratios, driven by a macroscopic Poisson ratio, is still 


\begin{tabular}{|c|c|c|c|c|c|}
\hline Combined regions & $\left(\mathrm{u}_{1}(\mathrm{~mm}), \mathrm{u}_{2}(\mathrm{~mm})\right)$ & $\bar{\sigma}_{1}\left(f_{1}\right) / \sigma_{c_{2}}$ & $\bar{\sigma}_{2}\left(f_{1}\right) / \sigma_{c_{2}}$ & $\bar{\sigma}_{1}\left(f_{2}\right) / \sigma_{c_{2}}$ & $\bar{\sigma}_{2}\left(f_{2}\right) / \sigma_{c_{2}}$ \\
\hline \multirow{9}{*}{ tension-tension } & $(0.01,0.0)$ & 0.265 & 0.085 & 0.278 & 0.093 \\
\hline & $(0.005,0.0087)$ & 0.232 & 0.275 & 0.225 & 0.273 \\
\hline & $(0.0087,0.005)$ & 0.273 & 0.233 & 0.284 & 0.249 \\
\hline & $(0.0,0.01)$ & 0.086 & 0.266 & 0.081 & 0.265 \\
\hline & $(0.0096,0.0026)$ & 0.274 & 0.171 & 0.274 & 0.164 \\
\hline & $(0.0026,0.0096)$ & 0.171 & 0.275 & 0.163 & 0.274 \\
\hline & $(0.0099,0.0013)$ & 0.271 & 0.130 & 0.271 & 0.124 \\
\hline & $(0.0038,0.0092)$ & 0.206 & 0.276 & 0.198 & 0.275 \\
\hline & $(0.01,0.01)$ & 0.264 & 0.262 & 0.274 & 0.274 \\
\hline \multirow[t]{7}{*}{ compression-compression } & $(-0.06,0.0)$ & -1.143 & -0.312 & -1.306 & -0.366 \\
\hline & $(-0.03,-0.05)$ & -0.803 & -1.116 & -0.937 & -1.301 \\
\hline & $(-0.05,-0.03)$ & -1.106 & -0.811 & -1.275 & -0.939 \\
\hline & $(0.0,-0.06)$ & -0.273 & -1.034 & -0.373 & -1.336 \\
\hline & $(-0.058,-0.015)$ & -1.443 & -0.575 & -1.323 & -0.664 \\
\hline & $(-0.06,-0.06)$ & -0.956 & -0.965 & -1.107 & -1.118 \\
\hline & $(-0.015,-0.058)$ & -0.509 & -1.156 & -0.668 & -1.362 \\
\hline \multirow[t]{4}{*}{ compression-tension } & $(-0.005,0.0087)$ & -0.146 & 0.229 & -0.179 & 0.239 \\
\hline & $(-0.0087,0.005)$ & -0.389 & 0.111 & -0.454 & 0.118 \\
\hline & $(-0.0071,0.0071)$ & -0.311 & 0.182 & -0.323 & 0.192 \\
\hline & $(-0.0061,0.0079)$ & -0.240 & 0.208 & -0.252 & 0.218 \\
\hline \multirow[t]{4}{*}{ tension-compression } & $(0.005,-0.0087)$ & 0.112 & -0.448 & 0.116 & -0.456 \\
\hline & $(0.0087,-0.005)$ & 0.231 & -0.151 & 0.236 & -0.179 \\
\hline & $(0.0071,-0.0071)$ & 0.185 & -0.316 & 0.190 & -0.324 \\
\hline & $(0.0061,-0.0079)$ & 0.154 & -0.383 & 0.157 & -0.392 \\
\hline
\end{tabular}

Table 4: Ratios of ultimate strength with respect to $\sigma_{c_{2}}$ along $\mathrm{X}$ and $\mathrm{Y}$ directions under different couples of imposed displacements for 15 and $35 \%$ of aggregates 


\begin{tabular}{|c|c|c|c|}
\hline Combined regions & $\left(\mathrm{u}_{1}(\mathrm{~mm}), \mathrm{u}_{2}(\mathrm{~mm})\right)$ & $\bar{\sigma}_{1}\left(f_{3}\right) / \sigma_{c_{2}}$ & $\bar{\sigma}_{2}\left(f_{3}\right) / \sigma_{c_{2}}$ \\
\hline \multirow{9}{*}{ tension-tension } & $(0.01,0.0)$ & 0.263 & 0.087 \\
\hline & $(0.005,0.0087)$ & 0.261 & 0.290 \\
\hline & $(0.0087,0.005)$ & 0.291 & 0.256 \\
\hline & $(0.0,0.01)$ & 0.100 & 0.291 \\
\hline & $(0.0096,0.0026)$ & 0.299 & 0.192 \\
\hline & $(0.0026,0.0096)$ & 0.196 & 0.289 \\
\hline & $(0.0099,0.0013)$ & 0.286 & 0.142 \\
\hline & $(0.0038,0.0092)$ & 0.235 & 0.290 \\
\hline & $(0.01,0.01)$ & 0.249 & 0.244 \\
\hline \multirow[t]{7}{*}{ compression-compression } & $(-0.06,0.0)$ & -1.400 & -0.277 \\
\hline & $(-0.03,-0.05)$ & -0.999 & -1.372 \\
\hline & $(-0.05,-0.03)$ & -1.327 & -0.857 \\
\hline & $(0.0,-0.06)$ & -0.280 & -1.383 \\
\hline & $(-0.058,-0.015)$ & -1.376 & -0.553 \\
\hline & $(-0.06,-0.06)$ & -1.195 & -1.137 \\
\hline & $(-0.015,-0.058)$ & -0.636 & -1.449 \\
\hline \multirow[t]{4}{*}{ compression-tension } & $(-0.005,0.0087)$ & -0.266 & 0.249 \\
\hline & $(-0.0087,0.005)$ & -0.537 & 0.123 \\
\hline & $(-0.0071,0.0071)$ & -0.391 & 0.197 \\
\hline & $(-0.0061,0.0079)$ & -0.415 & 0.224 \\
\hline \multirow[t]{4}{*}{ tension-compression } & $(0.005,-0.0087)$ & 0.128 & -0.517 \\
\hline & $(0.0087,-0.005)$ & 0.247 & -0.255 \\
\hline & $(0.0071,-0.0071)$ & 0.198 & -0.376 \\
\hline & $(0.0061,-0.0079)$ & 0.167 & -0.446 \\
\hline
\end{tabular}

Table 5: Ratios of ultimate strength with respect to $\sigma_{c_{2}}$ along $\mathrm{X}$ and $\mathrm{Y}$ directions under different couples of imposed displacements for $40 \%$ of aggregates 


\begin{tabular}{|c|c|c|c|c|}
\hline Combined regions & $\left(\mathrm{u}_{1}(\mathrm{~mm}), \mathrm{u}_{2}(\mathrm{~mm})\right)$ & $G_{f}\left(f_{1}\right)(\mathrm{J})$ & $G_{f}\left(f_{2}\right)(\mathrm{J})$ & $G_{f}\left(f_{3}\right)(\mathrm{J})$ \\
\hline tension-tension & $(0.01,0.01)$ & 5.671 & 6.417 & 6.703 \\
\hline compression-compression & $(-0.06,-0.06)$ & 57.056 & 65.048 & 110.505 \\
\hline compression-tension & $(-0.005,0.0087)$ & 15.692 & 17.493 & 23.039 \\
\hline tension-compression & $(0.005,-0.0087)$ & 15.672 & 17.502 & 22.091 \\
\hline
\end{tabular}

Table 6: Values of fracture energy under particular couples of imposed displacements for $15 \%, 35 \%$ and $40 \%$ of aggregates 
available. As for the second phase, it corresponds to a non-linear relation between the two ratios : cracking is then important and the behavior is no longer governed by a macroscopic Poisson modulus.

In the zone of compression-compression, a linear behavior is observed between $\bar{\sigma}_{1} / \sigma_{c_{2}}$ and $\bar{\sigma}_{2} / \sigma_{c_{2}}$ : cracks are prevented from opening (the loading in the $\mathrm{Y}$ direction tends to prevent the crack from opening in the $\mathrm{X}$ direction and the loading in the $\mathrm{X}$ direction tends to prevent the crack from opening in the $\mathrm{Y}$ direction), their influences is therefore less important than in the others cases of loading.

To conclude Section 3, one can say that Fig. [16 confirms the interest of concrete plasticity criterion, of multi-surface kind, with the compression described by Drucker-Prager kind of model [41] and tension regime described by Rankine model [42].

\section{Conclusion}

In this work, we proposed a novel constitutive model of plasticity suitable for describing the failure phenomena in two-phase composite materials, such as concrete with aggregates melt into a mortar matrix. Contrary to usual phenomenological models, the main features of the proposed model are not obtained from performing real experiments, but rather from numerical experiments carried out with a meso-scale Finite Element model. The mesomodel relies on a non-conforming mesh of spatial truss elements, representing aggregate, cement paste and interface so that some elements must be split into two parts. The latter requires introducing a weak discontinuity into the elements split by the phase interface, which provides an effective method to take into account inclusions without remeshing. Moreover, a strong discontinuity is introduced within each element at a particular instant of localized failure providing the capability to model crack opening. These key points provide an efficient tool to accomplish "virtual testing"; where changes in size, distribution and volume fraction of aggregates can easily be introduced.

Three types of concrete with different volume fractions $(15 \%, 35 \%$ and $40 \%)$ were tested. For these three specimens, failure surfaces and failure modes according to different loading combinations were developed. One can note that in the region of compression-compression 


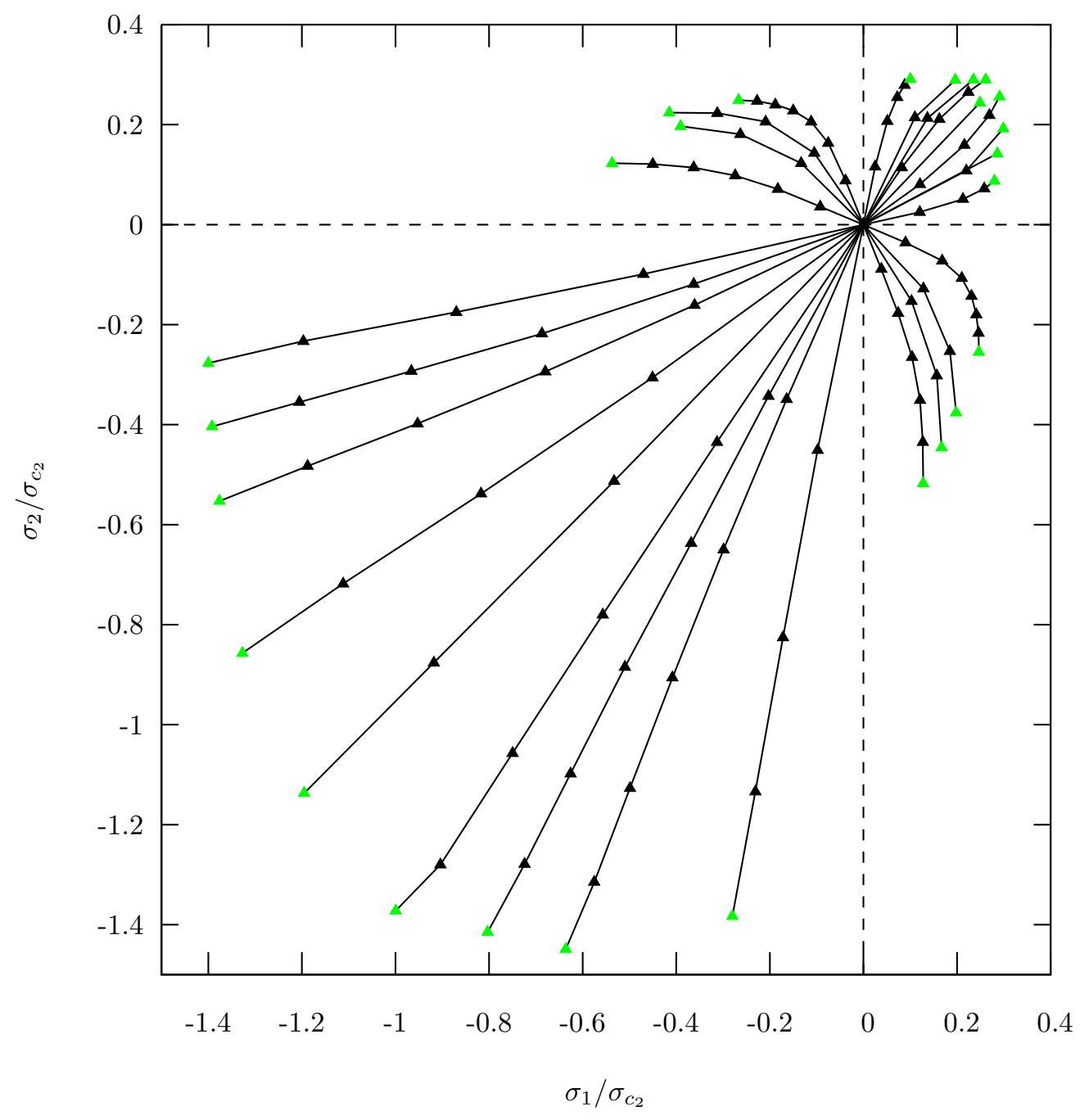

Figure 17: Evolution of $\sigma_{1} / \sigma_{c_{2}}$ with respect to $\sigma_{2} / \sigma_{c_{2}}$, during the loading until failure (green points), in the case of $40 \%$ of aggregates 
the ultimate strength rises up significantly with the percentage of inclusions whereas the three others regions are quasi independent of this percentage variation. It is important to stress the fact that the ultimate strength increase in relation to the uniaxial compression strength is dependant of the imposed displacements ratios in the region of compressioncompression, whereas the three others regions remain quasi independent of the same ratio. These two points are often confirmed as major features of quasi-brittle materials such as concrete.

Finally, the most notable finding is that this approach can provide the sound definitions of the parameters governing the failure process, such as the fracture energy, the ultimate strength taking into account the heterogeneity and different process of cracking and that can be used to identify the parameters of phenomenological models as multi-surface models (e.g. the combination of Rankine and Drucker-Prager criterion or the three-surface plasticity cap model [41]). Once these phenomenological models are clearly identified, a structural analysis could be performed with the potential to provide more predictive results from the classical phenomenological models.

In the future explorations, we plan to study how to account for induced anisotropy in the process of cracking. Thus, the additional computations will be performed for the numerical loading program on pre-cracked specimen where the initial crack can be computed from drying and early age models of concrete [43].

\section{References}

[1] J.-M. Reynouard, G. Pijaudier-Cabot, and J.-M. Torrenti. Mechanical behavior of concrete. Wiley, New-York, 2009.

[2] J. Lubliner. Plasticity Theory,. Mac-Millan, 1990, 1990.

[3] J. Lemaitre and J.-L. Chaboche. Mécanique des Matériaux Solides,. Dunod, 2004, 2004.

[4] A. Kucerova, D. Brancherie, A. Ibrahimbegovic, J. Zeman, and Z Bittnar. Novel anisotropic continuumdiscrete damage model capable of representing localized failure of massive structures. International Journal for Computer-Aided Engineering and Software, 26:128-144, 2009.

[5] W. Nechnech, F. Meftah, and J.-M. Reynouard. An elasto-plastic damage model for plain concrete subjected to high temperatures. Engineering and Structures, 24:597-611, 2002. 
[6] D. Brancherie and A. Ibrahimbegovic. Novel anisotropic continuum-discrete damage model capable of representing localized failure of massive structures. Engineering Computation, 26:128-144, 2009.

[7] N. Benkemoun, M. Hautefeuille, J.-B. Colliat, and A. Ibrahimbegovic. Modeling heterogeneous materials failure: 3D meso-scale models with embedded discontinuities. International Journal of Numerical Methods in Engineering, 82:1671-1688, 2010.

[8] P. Wriggers and S. O. Moftah. Mesoscale models for concrete: Homogenisation and damage behaviour. Finite Elements in Analysis and Design, 42:623-636, 2006.

[9] R. I. Borja and J. E. Andrade. Critical state plasticity, part VI: Meso-scale finite element simulation of strain localization in discrete granular materials. Computer Methods in Applied Mechanics and Engineering, 195:5115-5140, 2006.

[10] E. Schlangen and J. G. M. van Mier. Simple lattice model for numerical simulation of fracture of concrete materials and structures. Materials and Structures, 25:534-542, 1992.

[11] E. Schlangen and E. J. Garboczi. Fracture simulations of concrete using lattice models: computational aspects. Engineering Fracture Mechanics, 57:319-332, 1997.

[12] M. Yip, J. Mohle, and J. E. Bolander. Automated modeling of three-dimensional structural components using irregular lattices. Computer-Aided Civil and Infrastructure Engineering, 120:393-407, 2005.

[13] A. Lachihab and K. Sab. Aggregate composites: a contact based modeling. Computational Material Science, 33:467-490, 2005.

[14] M. Hautefeuille, S. Melnyk, J.-B. Colliat, and A Ibrahimbegovic. Failure model of heterogeneous structures using structured meshes and accounting for probability aspects. Engineering Computation, 26:166-184, 2009.

[15] N. Moës, M. Cloirec, P. Cartraud, and J.-F. Remacle. A computational approach to handle complex microstructure geometries. Computer Methods in Applied Mechanics and Engineering, 192:3163-3177, 2003.

[16] J. C. Simo, J. Oliver, and F. Armero. An analysis of strong discontinuities induced by strain-softening in rate independent inelastic solids. Computational Mechanics, 12:277-296, 1993.

[17] G. N. Wells and L. J. Sluys. Three-dimensional embedded discontinuity model for brittle fracture. International Journal of Solids and Structures, 38:897-913, 2001.

[18] J. Oliver, A. E Huespe, M. D. G Pulido, and E. Chaves. From continuum mechanics to fracture mechanics: the strong discontinuity approach. Engineering Fracture Mechanics, 69:113-136, 2002.

[19] J. Oliver. Modelling strong discontinuities in solid mechanics via strain softening constitutive equations. International Journal for Numerical Methods in Engineering, 39:3575-3623, 1996.

[20] D. Dias-da-Costa, J. Alfaiate, L. J. Sluys, and E. Júlio. A discrete strong discontinuity approach. Engineering Fracture Mechanics, 76:1176-1201, 2009. 
[21] K. Washizu. Variational Methods in Elasticity and Plasticity. Pergamon Press, New York, 3 edition, 1982.

[22] J.C. Simo and M. Rifai. A class of mixed assumed strain methods and the method of incompatible modes. International Journal of Numerical Methods in Engineering, 29:1595-1638, 1990.

[23] A. Ibrahimbegovic and E.L. Wilson. A modified method of incompatible modes. Communication in Applied Numerical Methods, 7:187-194, 1991.

[24] N. Moës, J. Dolbow, and T. Belytshko. A finite element method for crack growth without remeshing. International Journal of Numerical Methods in Engineering, 46:131-150, 1999.

[25] T. Strouboulis, I. Babuška, and K. Copps. The design and analysis of the Generalized Finite Element Method. Computer Methods in Applied Mechanics and Enginnering, 181:43-69, 2000.

[26] A. Ibrahimbegovic and S. Melnyk. Embedded discontinuity finite element method for modeling of localized failure in heterogeneous materials with structured mesh: an alternative to extended finite element method. Computational Mechanics, 40:149-155, 2007.

[27] A. Ibrahimbegovic. Non Linear Solid Mechanics : Theoretical Formulations and Finite Element Solution Methods. Springer, 2009.

[28] K. J. Bathe. Finite Element Procedures. Prentice Hall, 1996.

[29] N. Sukumar, D. L. Chopp, N. Moës, and T. Belytshcko. Modeling holes and inclusions by level sets in the extended finite element method. Computer Methods in Applied Mechanics and Engineering, 190:6183-6200, 2001.

[30] Z. Hashin and S. Shtrikman. A variational approach to the theory of the elastic behaviour of multiphase materials. Journal of the Mechanics and Physics of Solids, 11:127-140, 1963.

[31] C. Huet. An Integrated Approach of Concrete Micromechanics. in: Michromecanics of Concrete and Cementitious Composites. Presses Polytechniques et Universitaires Romandes, Lausanne, pp. 117-146, 1993.

[32] J. J. C. Pituba and G. R. Fernandes. An anisotropic damage model for the concrete. Journal of Engineering Mechanics, 2010.

[33] J. Mazars. Application de la mécanique de l'endommagement au comportement non linéaire et à la ruine du béton de structure. PhD thesis, Thèse d'état, Université Paris VI, Paris, 1984.

[34] G. D. Nguyen and G. T. Houlsby. A coupled damage-plasticity model for concrete based on thermodynamic principles: Part i: model formulation and parameter identification. International Journal for Numerical and Analytical Methods in Geomechanics, 32:353-389, 2008.

[35] I. Ö. Yaman, N. Hearn, and H. M. Aktan. Active and non-active porosity in concrete. part I: experimental evidence. Materials and Structures, 35:102-109, 2002.

[36] G. D. Nguyen and G. T. Houlsby. A coupled damage-plasticity model for concrete based on ther- 
modynamic principles: Part ii: non-local regularization and numerical implementation. International Journal for Numerical and Analytical Methods in Geomechanics, 32:391-413, 2008.

[37] L. Sang-Keun, S. Young-Chul, and H. Sang-Hoon. Biaxial behavior of plain concrete of nuclear containment building. Nuclear Engineering and Design, 227:143-153, 2004.

[38] H. Kupfer and H.K. Hilsdorf. Behavior of concrete under biaxial stress. ACI J. Proc. 66, 8:656-666, 1969.

[39] A. Carpinteri and A. R. Ingraffea. Fracture Mechanics of Concrete. Martinus Nijhoff editor, The Netherlands, 1984.

[40] E. Astudillo de la Vega. Étude expériementale du comportement mécanique d'un Béton Fibré à Ultra Hautes Performances (BFUHP) en traction biaxiale. PhD thesis, École Normale Supérieure de Cachan, 2002.

[41] S. Dolarevic and A. Ibrahimbegovic. A modified three-surface elasto-plastic cap model and its numerical implementation. Computer and Structures, 85:419-430, 2007.

[42] C.J. Pearce and N. Bicanic. On multi-surfaces plasticity and rankine model. in Owen, D.J.R., Onate, E. and Hinton, E. (Eds), Proceedings of CIMNE, Barcelona, Spain, 1997.

[43] C. De Sa, N. Benkemoun, J.-B. Colliat, and F. Benboudjema. Modélisation à l'échelle mesocopique du comportement hydro-mécanique des matériaux à matrice cimentaire. CSMA, Giens, 2009. 